Dorn, T., Yzermans, J., Spreeuwenberg, P., Schilder, A., Zee, J. van der. A cohort study of the long-term impact of a fire disaster on the physical and mental health of adolescents. Journal of Traumatic Stress: 2008, 21(2), 239-242

\begin{tabular}{|l|l|}
\hline Postprint Version & 1.0 \\
\hline Journal website & $\underline{\mathrm{http}: / / \text { www3.interscience.wiley.com/cgi-bin/abstract/118480020/ABSTRACT }}$ \\
\hline Pubmed link & $\underline{\mathrm{http}: / / \text { www.ncbi.nlm.nih.gov/pubmed/18404625 }}$ \\
\hline DOI & $10.1002 / \mathrm{jts} .20328$ \\
\hline
\end{tabular}

This is a NIVEL certified Post Print, more info at http://www.nivel.eu

\title{
The long-term impact of a fire disaster on the physical and mental health of adolescents - a cohort study
}

\author{
TINA DORN ${ }^{\mathrm{A}}$, Joris C. YZERMANS ${ }^{\mathrm{A}}$, PETER MM SPREEUWENBERG ${ }^{\mathrm{A}}$, AGATHA SCHILDER ${ }^{\mathrm{B}}$, \\ JOUKE VAN DER ZEE ${ }^{A}$

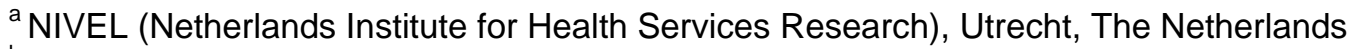 \\ ${ }^{\mathrm{b}}$ Medical Center Waterland Oost, Volendam, The Netherlands
}

\begin{abstract}
The literature on adult trauma survivors demonstrates that those exposed to traumatic stress have a poorer physical health status than non-exposed individuals. Studies on physical health effects in adolescent trauma survivors, in contrast, are scarce. In the current study, it was hypothesized that adolescents who have been involved in a mass burn incident $(N=124)$ will demonstrate more physical and mental health problems than an unaffected cohort from the same community $(N=1,487)$. Health data were extracted from electronic medical records, covering one year pre-fire and four years post-fire. When compared to the pre-fire baseline, survivors showed significantly larger increases in mental, respiratory and musculosceletal problems than community controls during the first year after the fire, but not during the later years.
\end{abstract}

Recent research demonstrates that trauma-exposed adults report a poorer health status than non-exposed individuals ( Boscarino, 2004; Kimerling, Clum, McQuery, \& Schnurr, 2002; Oilman \& Siegel, 2006). Research on physical health effects in younger age groups is scarce, however. In younger age groups, so far, most of the research has addressed mental health effects (Bolton, O'Ryan, Udwin, Boyle, \& Yule, 2000; Broberg, Dyregrov, \& Lilled, 2005; Goenjian et al., 2001; Goenjian et al., 2005; Yule et al., 2000).

The current prospective, record-based study provided the opportunity to examine both physical and mental health problems in a group of adolescents who survived a mass burn incident which occurred in a café-bar, in Volendam, the Netherlands, on New Year's Eve 2000. The bar was a popular meeting place for the town's young people. When the fire began, the bar was seriously overcrowded. Fourteen adolescents died due to the fire and more than 200 victims were treated in hospitals (Welling et al., 2005).

In order to separate the effects of psychological and physical trauma, the present study focusses on adolescents who were trapped in the fire, but did not suffer burns. These adolescents had experienced life-threat and witnessed how their peers were injured or died at 
Dorn, T., Yzermans, J., Spreeuwenberg, P., Schilder, A., Zee, J. van der. A cohort study of the long-term impact of a fire disaster on the physical and mental health of adolescents. Journal of Traumatic Stress: 2008, 21(2), 239-242

the scene. As a control group, adolescents from the same community who were not directly involved in the fire are examined.

\section{METHOD}

\section{Participants and Procedure}

Volendam has about 20,000 inhabitants. The population is served by four family practices. In the Netherlands, most contacts between the public at large and the health care system take place in family practice (FP). In our study, all FPs electronically registered their patients' health problems according to the International Classification of Primary Care (ICPC). The ICPC is an internationally endorsed classification system which is compatible with the ICD10 (Hofmans-Okkes \& Lamberts, 1996). The electronic registrations were already operational before the fire occurred, allowing for pre-post comparisons. The extracted data did not contain names or addresses and individuals could not be personally identified. Patients were invited to object against the use of their data, but no one disagreed.

Shortly after the fire, all four local family practices were asked to identify those youths who had been present during the fire in their registrations $(N=335)$. According to official figures, 300-350 persons were present when the fire occured. The number identified by the FPs thus closely approximated these estimates. One of the four practices was not yet fully automated and therefore could not participate in the study, leading to the exclusion of 35 survivors registered with this practice. Furthermore, those who lost their lives due to the fire $(n=14)$ and those who suffered burns $(n=162)$ were excluded from the analyses, resulting in a final sample of $n=124$ adolescents. Next to this, from the patient lists of the three participating FP practices, we selected all those aged 13-23 who had not been present during the incident. Since most survivors (122 out of 124) were still living with their parents, as controls, we only chose those also cohabiting with their parents. This resulted in a cohort of 1,487 community controls (Dorn, Yzermans, Kerssens, Spreeuwenberg, \& van der Zee, 2006).

\section{Measures}

Mental health problems were defined as problems belonging to the ICPC-chapters $\mathrm{P}$ (psychological) and Z (social). In addition, physical health problems as summarized in the ICPC-chapters L (musculoskeletal), R (respiratory), D (gastrointestinal) and S (dermatological) were analyzed. These chapters were selected for analysis due to their high prevalence.

Five different time periods were distinguished: (1) the 12 month period prior to the fire (year 2000), (2) 0-12 months post-fire (year 2001), (3) 13-24 months post-fire (year 2002), (4) 25-36 months post-fire (year 2003) and (5) 37-48 months post-fire (year 2004). If a patient presented the same health problem several times in a year, it was counted as one problem. Patients who did not contact the FP for health problems in a year received a count of zero.

\section{Data Analysis}

Patient characteristics were compared using one-way ANOVA or chi-square tests. The multivariate analysis was based on logistic regression models. In order to account for the repeated measurements in our study, a multilevel framework was chosen, with person and measurement occasion as levels (Snijder \& Bosker, 1999). The outcome measure in the regression analyses was the presence or absence of a health problem (musculoskeletal, gastrointestinal, dermatological, respiratory, or mental; coded 1 if present, and 0 if absent). The four years of the study were dummy-coded (omitted category: year pre-fire) and one dummy was introduced for group membership (survivors coded as 1, controls coded as 0 ). In order to test the difference in change between the two groups, interaction terms of group and year were introduced. As covariates, dummies for family practice and insurance type were included. Since there were no differences between survivors and controls with respect to gender and age, we did not adjust for the influence of these variables. 
Dorn, T., Yzermans, J., Spreeuwenberg, P., Schilder, A., Zee, J. van der. A cohort study of the long-term impact of a fire disaster on the physical and mental health of adolescents. Journal of Traumatic Stress: 2008, 21(2), 239-242

\section{RESULTS}

Survivors $(n=124)$ were comparable to community controls $(n=1487)$ with respect to gender and age. The mean age of survivors was 17.8 years $(S D=2,85)$, compared to 17.46 $(S D=2,94)$ in controls. Slightly more than half of the survivors and controls were male (53.2\% and 54.4\%, respectively). Survivors were less often privately insured than controls $\left(\chi^{2}(1, N=1611)=5.84, p<.05\right)$. In 2001, survivors displayed significantly larger increases of musculoskeletal $(\beta=0.046, B=0.670, S E=0.269, p<.05)$, respiratory $(\beta=0.088, B=$ $1.290, S E=0.291, p<.001)$ and mental problems $(\beta=0.141, B=2.056, S E=0.328, p<$ $.001)$ when compared to controls (Table 1). In the second, third and fourth year after the fire, survivors did not significantly differ from controls in any of the studied areas.

\section{DISCUSSION}

In the current study, physical health effects in survivors of the Volendam pub fire were limited to the first year post-disaster and they were only observed in the musculoskeletal and respiratory domains. Part of this morbidity seen on the short term can be attributed to the physical exposure to the fire. Respiratory problems may be the result of smoke inhalation, and musculoskeletal problems might be the result of trying to flee the burning building. In another study on adolescents exposed to a large-scale disaster, significant increases in musculoskeletal problems were reported after exposure, too (Dirkzwager, Kerssens \& Yzermans, 2006). In this study, effects were restricted to the first year after the event, as well.

More important, however, is the finding that long-term physical health effects in our sample were absent. Two explanations can be offered for this finding. Either, adolescents are better protected against the (somatic) effects of psychological trauma, or the time-frame of our study was too short to demonstrate long-term effects. Schnurr and colleagues emphasize that adverse physical health outcomes are often the product of cumulative, interactive effects of factors that alone (or in a short time frame) may have only minimal or transient effects that would be insufficient to induce disease (Schnurr et al., 1999, Schnurr \& Green, 2004). A longer follow-up period therefore might be necessary if long-term effects are to be detected in adolescent populations.

\section{[TABLE 1]}

Next to this, the current study provided evidence for an increased prevalence of mental health problems in survivors when compared to community controls during the first year after the fire. This finding is in line with numerous other reports (Bolton, O'Ryan, Udwin, Boyle, \& Yule, 2000; Broberg, Dyregrov, \& Lilled, 2005; Goenjian et al., 2001; Goenjian et al., 2005; Yule et al., 2000). On the longer term, however, differences between the two cohorts did not reach statistical significance. This might be attributed to the fact that the percentage of adolescents who discussed mental health problems with their family practitioner prior to the disaster was low, resulting in a lack of statistical power. Moreover, survivors and controls in the current study were sampled from the same community. Although youngsters included in the control group had not been trapped in the fire themselves, it affected their friends, extended families or classmates. The community controls therefore might have suffered from the consequences of the fire, as well. Althogether, this may have led to an underestimation of the mental health effects in the survivors studied here. Ideally, a second control group should have been established, consisting of adolescents from an unaffected community. This was done in two previous studies on the mental health of Voldendam adolescents. In these questionnaire-based studies, assessments were carried out 5 and 12 months after the fire and compared to pre-disaster data (Reijneveld, Crone, Verhulst, \& Verloove-Vanhorick, 2003; Reijneveld, Crone, Schuller, Verhulst, \& Verloove-Vanhorick, 2005). Data were based on samples of Volendam adolescents (a group largely equivalent to the community controls studied here) and controls 
Dorn, T., Yzermans, J., Spreeuwenberg, P., Schilder, A., Zee, J. van der. A cohort study of the long-term impact of a fire disaster on the physical and mental health of adolescents. Journal of Traumatic Stress: 2008, 21(2), 239-242

from two control schools outside Volendam. The first study showed that Volendam adolescents had larger increases in clinical scores than controls and excessive use of alcohol. The second assessment demonstrated differences between controls and Volendam adolescents in regard to excessive drinking only.

Another point of concern is the reliability and validity of FPs judgement of mental health issues. Considering that the Volendam fire disaster occurred in a close-knit community, it can be assumed that FPs encouraged their patients to discuss mental health issues during consultations, especially immediately after the disaster when there was a lot of attention for the mental health consequences of the event. It is possible that in the later years, the diagnostic focus of FPs shifted towards somatic complaints and mental health problems were underdiagnosed. In our study, we were not able to assess this issue directly since FP patients could not be addressed personally due to privacy regulations. It would have been ideal to assess mental health problems in these patients through standardized questionnaires or diagnostic interviews and to compare these data with FP diagnoses in the course of time.

Finally, it should be noted that conceptual models are needed in order to guide researcher's thinking when carrying out studies in the area of posttraumatic stress and health. In the current case, for example, it would have been desirable to assess posttraumatic stress in the exposed population through standardized questionnaires or diagnostic interviews. This would have allowed for testing whether PTSD symptomatology predicts physical health problems in a later stage or not. For a better understanding of the underlying processes, future studies therefore should consider combining the benefits of record-based research with complementary data from other sources.

\section{ACKNOWLEDGEMENTS}

This study was financially supported by the Dutch Ministry of Health. We thank all Volendam family practitioners for the provision of the data and Petra ten Veen for the management of the database.

\section{RUNNING HEAD}

Long-term impact of a fire disaster on physical and mental health of adolescents

\section{REFERENCE LIST}

Bolton, D., O'Ryan, D., Udwin, O., Boyle, S., \& Yule, W. (2000). The long-term psychological effects of a disaster experienced in adolescence: II: General psychopathology. Journal of Child Psychology and Psychiatry and Allied Disciplines, 41, 513-523.

Boscarino, J. A. (2004). Posttraumatic stress disorder and physical illness: results from clinical and epidemiologic studies. Annals of the New York Academy of Science., 1032, 141-153.

Broberg, A. G., Dyregrov, A., \& Lilled, L. (2005). The Goteborg discotheque fire: posttraumatic stress, and school adjustment as reported by the primary victims 18 months later. Journal of Child Psychology and Psychiatry, 46, 1279-1286.

Dirkzwager, A. J., Kerssens, J. J., \& Yzermans, C. J. (2006). Health problems in children and adolescents before and after a man-made disaster. Journal of the American Academy of Child and Adolescent Psychiatry, 45, 94-103.

Dorn, T., Yzermans, C. J., Kerssens, J. J., Spreeuwenberg, P. M., \& van der, Zee, J. (2006). Disaster and subsequent healthcare utilization: a longitudinal study among victims, their family members, and control subjects. Medical Care, 44, 581-589.

Goenjian, A. K., Molina, L., Steinberg, A. M., Fairbanks, L. A., Alvarez, M. L., Goenjian, H. A. et al. (2001). Posttraumatic stress and depressive reactions among Nicaraguan adolescents after hurricane Mitch. American Journal of Psychiatry, 158, 788-794. 
Dorn, T., Yzermans, J., Spreeuwenberg, P., Schilder, A., Zee, J. van der. A cohort study of the long-term impact of a fire disaster on the physical and mental health of adolescents. Journal of Traumatic Stress: 2008, 21(2), 239-242

Goenjian, A. K., Walling, D., Steinberg, A. M., Karayan, I., Najarian, L. M., \& Pynoos, R. (2005). A prospective study of posttraumatic stress and depressive reactions among treated and untreated adolescents 5 years after a catastrophic disaster. American Journal of Psychiatry, 162, 2302-2308.

Hofmans-Okkes, I. M. \& Lamberts, H. (1996). The International Classification of Primary Care (ICPC): new applications in research and computer-based patient records in family practice. Family Practice, 13, 294-302.

Jones, R.T., Ribbe, D.P., \& Cunningham, P.B. (1994). Psychosocial correlates of fire disaster among children and adolescents. Journal of Traumatic Stress, 7, 117-122.

Kimerling, R., Clum, G., McQuery, J., \& Schnurr, P. P. (2002). PTSD and medical comorbidity. In P.Ouimette \& a. et (Eds.), Gender and PTSD (pp. 271-302). New York, NY, US: Guilford Press.

Oilman, S.E., Siegel, J.M. (2006). Traumatic events and physical health in a community sample. Journal of Traumatic Stress, 9, 703-720.

Reijneveld, S. A., Crone, M. R., Schuller, A. A., Verhulst, F. C., \& Verloove-Vanhorick, S. P. (2005). The changing impact of a severe disaster on the mental health and substance misuse of adolescents: follow-up of a controlled study. Psychological Medicine, 35, 367376.

Reijneveld, S. A., Crone, M. R., Verhulst, F. C., \& Verloove-Vanhorick, S. P. (2003). The effect of a severe disaster on the mental health of adolescents: a controlled study. Lancet, 362, 691-696.

Schnurr, P. P. \& Green, B. L. (2004). Understanding relationships among trauma, posttraumatic stress disorder, and health outcomes. In B.L.Green \& P. P. Schnurr (Eds.), Trauma and health: Physical health consequences of exposure to extreme stress (pp. 247275). Washington, DC, US: American Psychological Association.

Snijder, T. B. \& Bosker, R. (1999). Multilevel analysis: an introduction to basic and advanced multilevel modeling. Thousand Oaks, CA: Sage.

Welling, L., van Harten, S. M., Patka, P., Bierens, J. J., Boers, M., Luitse, J. S. et al. (2005). The cafe fire on New Year's Eve in Volendam, the Netherlands: description of events. Burns, 31, 548-554.

Yule, W., Bolton, D., Udwin, O., Boyle, S., O'Ryan, D., \& Nurrish, J. (2000). The long-term psychological effects of a disaster experienced in adolescence: I: The incidence and course of PTSD. Journal of Child Psychology and Child Psychiatry, 41, 503-511. 
Dorn, T., Yzermans, J., Spreeuwenberg, P., Schilder, A., Zee, J. van der. A cohort study of the long-term impact of a fire disaster on the physical and mental health of adolescents. Journal of Traumatic Stress: 2008, 21(2), 239-242

\section{TABLE}

Table 1. Percentage of Survivors $(n=124)$ and Controls $(n=1,487)$ presenting Health Problems to the Family Practitioner

\begin{tabular}{|c|c|c|c|c|c|c|c|c|c|}
\hline & $\begin{array}{c}2000 \\
\text { (Prefire) }\end{array}$ & $\begin{array}{c}2001 \\
\text { (Postfire) }\end{array}$ & $\begin{array}{c}2002 \\
\text { (Postfire) }\end{array}$ & $\begin{array}{c}2003 \\
\text { (Postfire) }\end{array}$ & $\begin{array}{c}2004 \\
\text { (Postfire) }\end{array}$ & $\begin{array}{l}\text { Difference in } \\
\text { change between } \\
\text { groups: } \\
2000-2001\end{array}$ & $\begin{array}{l}\text { Difference in } \\
\text { change between } \\
\text { groups: } \\
2000-2002\end{array}$ & $\begin{array}{l}\text { Difference in } \\
\text { change between } \\
\text { groups: } \\
2000-2003\end{array}$ & $\begin{array}{l}\text { Difference in } \\
\text { change between } \\
\text { groups: } \\
2000-2004\end{array}$ \\
\hline \multicolumn{10}{|c|}{ Musculoskeletal } \\
\hline Survivors & 41.9 & 55.6 & 51.2 & 37.4 & 49.6 & * & $n s$ & $n s$ & $n s$ \\
\hline Controls & 29.8 & 30.2 & 31.7 & 31.1 & 28.6 & & & & \\
\hline \multicolumn{10}{|c|}{ Gastrointestinal } \\
\hline Survivors & 18.5 & 20.2 & 18.7 & 17.9 & 13.8 & $n s$ & $n s$ & $n s$ & $n s$ \\
\hline Controls & 11.1 & 12.0 & 11.1 & 13.6 & 10.9 & & & & \\
\hline \multicolumn{10}{|c|}{ Dermatological } \\
\hline Survivors & 47.6 & 45.2 & 47.2 & 37.4 & 35.0 & ns & $n s$ & ns & $n s$ \\
\hline Controls & 35.4 & 35.5 & 33.9 & 33.8 & 30.2 & & & & \\
\hline \multicolumn{10}{|l|}{ Respiratory } \\
\hline Survivors & 50.0 & 74.2 & 52.8 & 52.0 & 40.7 & $* * *$ & $n s$ & $n s$ & $n s$ \\
\hline Controls & 30.0 & 32.1 & 31.6 & 30.5 & 22.7 & & & & \\
\hline \multicolumn{10}{|l|}{ Mental } \\
\hline Survivors & 7.3 & 33.9 & 14.6 & 10.6 & 13.0 & $* * *$ & $n s$ & $n s$ & $n s$ \\
\hline Controls & 3.3 & 6.6 & 6.1 & 6.7 & 5.6 & & & & \\
\hline
\end{tabular}

Note. Date of the fire: January 1, 2001

${ }^{* *} p<.05 .{ }^{* * *} p<.001$. (Terms in a logistic model, adjusted for the influence of insurance type and family practice) 